\title{
Structure-Activity Relationship Studies and Molecular Modeling of Naphthalene-Based Sphingosine Kinase 2 Inhibitors
}

\author{
Molly D. Congdon, ${ }^{\dagger}$ Yugesh Kharel, ${ }^{\prime}$ Anne M. Brown, ${ }^{\dagger}$ Stephanie N. Lewis, ${ }^{\ddagger}$ David R. Bevan, ${ }^{\ddagger}$ \\ Kevin R. Lynch," and Webster L. Santos $* \dagger, \S$ \\ ${ }^{\dagger}$ Department of Chemistry, ${ }^{\ddagger}$ Department of Biochemistry, and ${ }^{\S}$ Virginia Tech Center for Drug Discovery, Virginia Tech, Blacksburg, \\ Virginia 24061, United States \\ "Department of Pharmacology, University of Virginia, Charlottesville, Virginia 22908, United States
}

\section{Supporting Information}

\begin{abstract}
The two isoforms of sphingosine kinase (SphK1 and SphK2) are the only enzymes that phosphorylate sphingosine to sphingosine-1-phosphate (S1P), which is a pleiotropic lipid mediator involved in a broad range of cellular processes including migration, proliferation, and inflammation. SphKs are targets for various diseases such as cancer, fibrosis, and Alzheimer's and sickle cell disease. Herein, we disclose the structure-activity profile of naphthalene-containing SphK inhibitors and molecular modeling studies that reveal a key molecular switch that controls SphK selectivity.
\end{abstract}

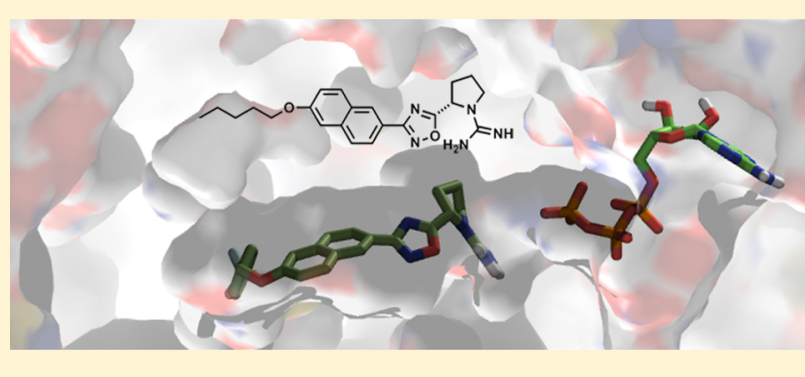

KEYWORDS: Sphingosine, sphingosine-1-phosphate, sphingosine kinase, structure-activity relationship, molecular docking

S phingolipids not only play a central role in eukaryotic membrane structural integrity but also in cell signaling pathways. Catabolism of sphingolipids generates ceramide, sphingosine, and sphingosine-1-phosphate (S1P), the concentrations of which are controlled by their respective enzymes. Studies have shown that these cellular metabolites can regulate the growth and survival balance of the cell. ${ }^{1,2}$ Ceramide and sphingosine are pro-apoptotic, while S1P promotes cell proliferation. S1P acts as a ligand to five G-protein coupled receptors (S1P1-5), which leads to diverse physiological and pathophysiological processes. The druggability of the S1P pathway was validated with the approval of fingolimod (Gilenya) by the FDA for relapsing remitting multiple sclerosis. 3,4

Sphingosine kinases (SphK) catalyze the phosphorylation of sphingosine to S1P. The S1P generated functions in a paracrine and autocrine fashion and regulates a complex signaling network to elicit a specific response such as migration and proliferation. SphKs exist in two isoforms, SphK1 and SphK2, which are localized in different compartments of the cell. ${ }^{5}$ A variety of diseases such as cancer, Alzheimer's disease, fibrosis, multiple sclerosis, and sickle cell disease are implicated with S1P signaling pathway. ${ }^{6-10}$ Therefore, controlling in vivo levels of S1P as a therapeutic modality is an attractive approach for these diseases. For example, S1P neutralizing antibodies such as sonepcizumab are currently undergoing clinical trials for age-related macular degeneration (NCT01414153) and advanced solid tumors (NCT00661414). ${ }^{11}$ SphK inhibitors are a complementary therapeutic strategy. ${ }^{12}$ Drug discovery campaigns have been deployed to develop isoform-selective SphK inhibitors (Figure 1). In particular, SphK1 has been a major focus by both academia and the pharmaceutical industry as an oncology target. ${ }^{13}$ For

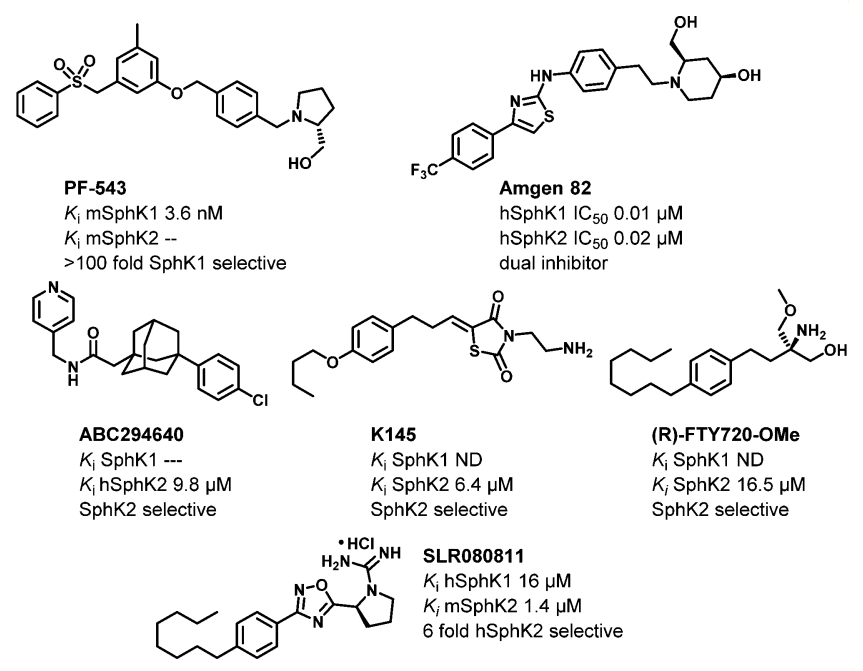

Figure 1. Select structures of sphingosine kinase inhibitors.

example, a SphK1 selective inhibitor, PF543 $\left(K_{\mathrm{i}} 3.5 \mathrm{nM},>100\right.$ fold selective), decreased in vivo S1P levels that correlated with reduced sickling of red blood cells in a mouse model of sickle cell disease. $^{9}$ A dual inhibitor, Amgen 82, had no statistical effect in reducing tumor volume in a xenograft mouse model. ${ }^{14}$ Comparatively, there are a limited number of SphK2 specific inhibitors reported, and these have $K_{\mathrm{i}}$ values in the $1-10 \mu \mathrm{M}$

Received: July 31, 2015

Accepted: February 2, 2016

Published: February 2, 2016 
Scheme $1^{a}$<smiles>N#Cc1ccc2cc(O)ccc2c1</smiles><smiles>[R10]Oc1ccc2cc(-c3noc([C@@H]4NCC[C@H]4[R])n3)ccc2c1</smiles><smiles>[R20]c1ccc2cc(-c3noc([C@@H]4[C@@H]([R2])CCN4C(=N)NCCl)n3)ccc2c1</smiles>

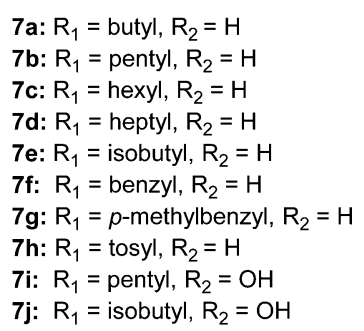

${ }^{a}$ Reagents and conditions: (a) R- $\mathrm{Br}$ or $\mathrm{TsCl}$ (1.2 equiv), $\mathrm{K}_{2} \mathrm{CO}_{3}$ (4 equiv), $\mathrm{CH}_{3} \mathrm{CN}, 80{ }^{\circ} \mathrm{C}, 4-12 \mathrm{~h}(84-100 \%)$; (b) $\mathrm{NH} \mathrm{H}_{2} \mathrm{OH} \cdot \mathrm{HCl},(3$ equiv), TEA (3 equiv), EtOH, $80^{\circ} \mathrm{C}, 6 \mathrm{~h}$ (67-98\%); (c) Boc-L-proline or (3S)-hydroxy-Boc-L-proline (1.4 equiv), DIEA (1.4 equiv), HCTU (1.8 equiv), DMF, $110{ }^{\circ} \mathrm{C}, 18 \mathrm{~h}$ (13-90\%); (d) $\mathrm{HCl} / \mathrm{MeOH}$ (42-100\%); (e) DIEA (3 equiv), $N, N$-DiBoc- $1 H$-pyrazole-1-carboxamidine (1.05 equiv), $\mathrm{CH}_{3} \mathrm{CN}, \mathrm{rt}, 3$ days $(27-84 \%)$.

Scheme $2^{a}$

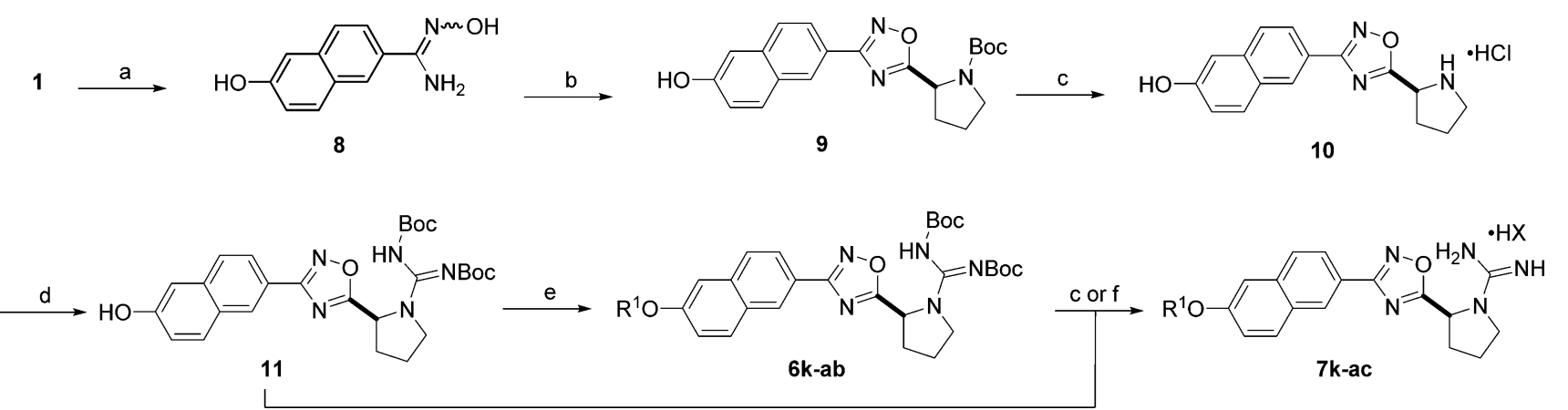

${ }^{a}$ Reagents and conditions: (a) $\mathrm{NH}_{2} \mathrm{OH} \cdot \mathrm{HCl}$, (2 equiv), TEA ( 3 equiv), EtOH, $150{ }^{\circ} \mathrm{C}, 2$ min (49\%); (b) Boc-L-proline (1.1 equiv), DIEA ( 3 equiv), PyBOP (1.2 equiv), DMF, $110^{\circ} \mathrm{C}, 18 \mathrm{~h},(58 \%)$; (c) $4 \mathrm{~N} \mathrm{HCl} /$ dioxane, $100{ }^{\circ} \mathrm{C}, 1 \mathrm{~min}$, microwave, (66-96\%); (d) DIEA (3 equiv), N,N-DiBoc-1Hpyrazole-1-carboxamidine (0.8 equiv), $\mathrm{CH}_{3} \mathrm{CN}, 85^{\circ} \mathrm{C}, 30 \mathrm{~min}$, microwave (35\%); (e) $\mathrm{R}-\mathrm{Br}$ (1.2 equiv), $\mathrm{K}_{2} \mathrm{CO}_{3}$ ( 2 equiv), $\mathrm{NaI}(0.1$ equiv), EtOH, $100{ }^{\circ} \mathrm{C}, 15 \mathrm{~min}$, microwave, (5-24\%); (f) TFA/DCM (47-93\%).

range. ABC294640 $0^{15,16}$ was the first selective SphK2 inhibitor $\left(K_{\mathrm{i}}\right.$ $9.8 \mu \mathrm{M})$ disclosed and is currently in phase I clinical trials for pancreatic cancer and solid tumors (NCT01488513), and refractory/relapsed diffuse large B-cell lymphoma (NCT02229981). Recent studies suggest that ABC294640 has a tamoxifen-like activity. ${ }^{17}$

As a result of our interest in understanding the in vivo function of SphK2, our investigations focus on identifying improved inhibitors of SphK2. We previously established the requirement for a positively charged "warhead" that is proposed to interact with key amino acid Asp residues in the enzyme binding pocket. ${ }^{18,19}$ Further structure-activity studies resulted in the discovery of SLR080811, which featured a 1,2,4-oxadiazole linker and a cationic guanidine headgroup. ${ }^{20}$ SLR080811 was the first SphK2 inhibitor to demonstrate an increase in blood S1P levels on dosing in mice. ${ }^{21}$ Although this finding was surprising, it is in agreement with genetic studies with SphK2 null mice wherein
S1P levels increased 2-3-fold over wild-type. ${ }^{2-24}$ Subsequent studies of the tail region of SLR080811 demonstrated the necessity for the internal phenyl ring and a dependence of SphK2 inhibitory activity with alkyl chain length. ${ }^{19,25}$ In this report, we detail our investigations on the tail region of a scaffold that features a naphthalene ring wherein a benzyltrifluoromethyl "tail" resulted in a $K_{\mathrm{i}}$ of $1 \mu \mathrm{M}$ and $>20$-fold selectivity toward SphK2. Molecular modeling efforts revealed key hydrophobic and hydrogen bonding interactions within the sphingosine binding pocket. In addition, structure-activity relationship studies indicated that removal of a hydroxyl group on the pyrrolidine ring of the inhibitor acts as a molecular switch to induce selective SphK2 inhibition.

The synthesis of the naphthalene containing SLR080811 derivatives are shown in Schemes 1 and 2. In Scheme 1, 6hydroxy-2-naphthonitrile 1 was coupled to a series of primary alkyl bromides or tosyl chloride using standard Williamson ether 
Table 1. Inhibitory Effects of Compounds with SphK1 and SphK2 ${ }^{a}$

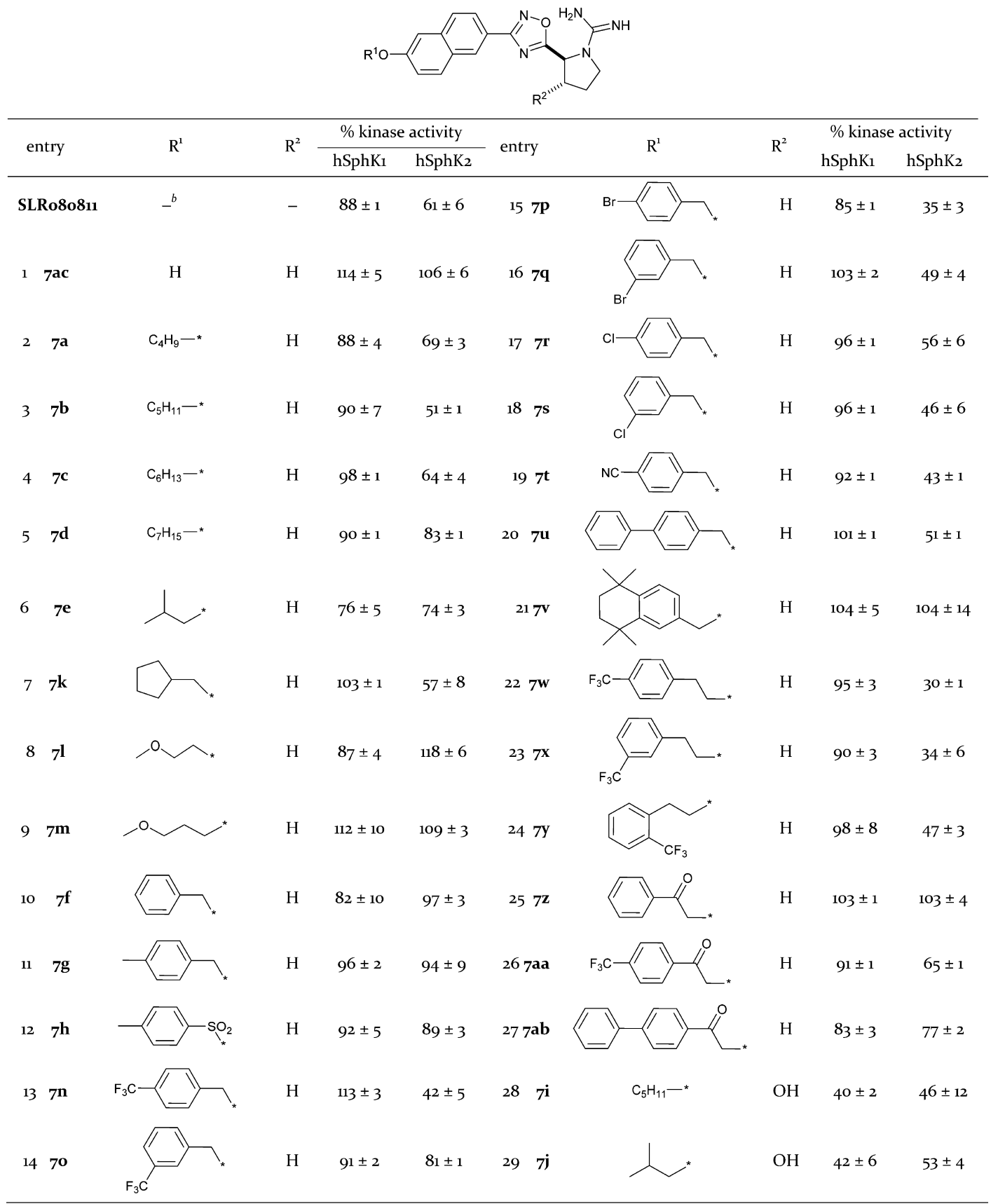

${ }^{a}$ Values are percent activity of hSphK1 or hSphK2 with 10 and $5 \mu \mathrm{M}$ Sph, respectively, in the presence of $1 \mu \mathrm{M}$ inhibitor. Each value is an average of three experiments. Lower SphK activity level indicates better inhibition. ${ }^{b}$ See Figure 1 for structure. The $K_{\mathrm{m}}$ of $\mathrm{SphK} 1$ and $\mathrm{SphK} 2$ is 10 and $5 \mu \mathrm{M}$, respectively.

synthesis conditions to afford naphthylether $\mathbf{2 a}-\mathbf{h}$. Subsequent reaction with hydroxylamine hydrochloride and triethylamine yielded amidoxime $\mathbf{3} \mathbf{a}-\mathbf{h}$. Treatment of $\mathbf{3} \mathbf{a}-\mathbf{h}$ with Boc-L-proline or (3S)-hydroxy-Boc-L-Proline and HCTU produced 1,2-4oxadiazole $4 \mathbf{a}-\mathbf{j}$. The Boc group was removed in acidic methanol to give pyrrolidine $\mathbf{5 a}-\mathbf{j}$, which was subsequently reacted with DIEA and $N, N^{\prime}$-Di-Boc- $1 H$-pyrazole-1-carboxamidine for several days at room temperature to generate intermediate $\mathbf{6 a}-\mathbf{j}$. It should be noted that the guanidylation reaction was most efficient following these conditions as heating resulted in decomposition. Removal of the Boc groups with $\mathrm{HCl}$ produced the desired guanidine derivatives $7 \mathbf{a}-\mathbf{j}$. To rapidly access a more diverse set of analogues, a common intermediate pathway was implemented using naphthol $\mathbf{1 1}$ as a key diversifying element as shown in Scheme 2.

With necessary compounds at hand, the inhibitory effects on human SphK1 and SphK2 were determined using a previously established protocol. ${ }^{26}$ In this assay, cell lysate containing recombinant human SphK1 or SphK2, sphingosine, and $\left[\gamma-{ }^{32} \mathrm{P}\right]$ ATP with or without inhibitor were incubated for 20 min. After extraction, the resulting mixture was separated by thin layer chromatography and quantified by scintillation counting. SphK activity was determined by the amount of $\left[\gamma^{32} \mathrm{P}\right]-\mathrm{S} 1 \mathrm{P}$ as a 
function of inhibitor concentration. Compounds were screened at $1 \mu \mathrm{M}$ inhibitor concentrations.

The results of the inhibition assay are shown in Table 1 with SLR080811 as the standard. As expected, removal of the lipophilic tail completely abolished inhibitory activity (entry 1). Incremental increases of an aliphatic chain from a short butyl to a longer heptyl group demonstrated a length dependence on inhibition (entries 2-5). In this series, optimal alkyl chain length is achieved with a pentyl group $(7 \mathbf{b})$, where the distance between the charged guanidine group and the omega carbon is approximately 19 atoms away. Compound $7 \mathbf{b}$ is slightly more potent than lead compound SLR080811. The cyclopentyl derivative $7 \mathbf{k}$ had similar activity, while a branched alkane (7e) or introduction of an ether linkage at the omega carbon did not improve kinase inhibition (entries 6-9). Substitution with a benzyl (7f), para-methylbenzyl (7g), or a tosyl (7h) group resulted in minimal inhibition (entries 10-12). However, placement of a 4-trifluoromethylbenzyl group $(7 \mathbf{n})$ resulted in significant inhibition of SphK2 without any inhibition of SphK1 at $1 \mu \mathrm{M}$ inhibitor concentration. As this $\mathrm{CF}_{3}$ group can impart SphK2 selectivity, the corresponding meta version (7o) was generated, but it was less potent; however, a series of halogens $(\mathrm{Br}$ and $\mathrm{Cl}$ ) in the meta and para positions as well as a small 4-cyano $(7 \mathbf{t})$ or phenyl $(\mathbf{7 u})$ group were equally potent (entries $15-20)$. A larger, hydrophobic 1,1,4,4-tetramethyltetralin (7v) was found to be inactive. To determine the optimal chain length for $7 \mathbf{n}$, homologated versions bearing the $\mathrm{CF}_{3}$ around the benzene ring $(7 \mathbf{w}-\mathbf{x})$ were tested and found to have slightly better activity. The ketone counterparts were found to induce minimal amounts of inhibition in SphK1 and SphK2 (entries 25-27). Finally, we installed a hydroxyl moiety on the pyrrolidine ring of one of the most potent and selective inhibitors in the series $(7 \mathbf{b})$ and a less potent, dual inhibitor (7e) to mimic one of the hydroxyl groups of sphingosine-1-phosphate to afford $7 \mathbf{i}$ and $7 \mathbf{j}$, respectively. These compounds were found to be potent inhibitors of both SphK1 and SphK2 (entries 28-29).

To further characterize the activity of inhibitors with SphK1 and SphK2, we selected representative inhibitors for further studies. As shown in Table 2, when a trans-hydroxyl group was installed on the pentyl (SLC5111312, 7i) and isobutyl (SLC5121314, 7j) derivatives, equipotent inhibition of SphK1

Table 2. Inhibition Constants of Select Inhibitors

\begin{tabular}{|c|c|c|c|c|c|}
\hline \multirow[b]{2}{*}{ compound } & \multicolumn{2}{|c|}{$K_{\mathrm{i}}(\mu \mathrm{M})^{a}$} & \multirow[b]{2}{*}{$\begin{array}{c}\text { hSphK2 } \\
\text { selectivity }\end{array}$} & \multirow[b]{2}{*}{ cLogP } & \multirow[b]{2}{*}{$\begin{array}{l}\text { cLogD } \\
(7.4)\end{array}$} \\
\hline & hSphK1 & hSphK2 & & & \\
\hline SLR080811 & $16 \pm 2.9$ & $1.4 \pm 0.2$ & 11 & 5.2 & 2.66 \\
\hline $\begin{array}{l}\text { SLC5111312 } \\
(7 \mathbf{i})\end{array}$ & $0.73 \pm 0.2$ & $0.90 \pm 0.2$ & 0.8 & 3.0 & 0.60 \\
\hline $\begin{array}{l}\text { SLC5121314 } \\
(7 \mathbf{j})\end{array}$ & $0.93 \pm 0.1$ & $0.98 \pm 0.3$ & 0.9 & 2.3 & 0.14 \\
\hline $\begin{array}{l}\text { SLC5081308 } \\
(7 \mathbf{b})\end{array}$ & $7.2 \pm 0.9$ & $0.98 \pm 0.2$ & 7.3 & 4.2 & 1.70 \\
\hline $\begin{array}{l}\text { SLC5011416 } \\
(7 \mathrm{c})\end{array}$ & $>10$ & $3.8 \pm 0.8$ & $>2.6$ & 4.7 & 2.12 \\
\hline $\begin{array}{l}\text { SLC5091592 } \\
(7 \mathbf{n})\end{array}$ & $>20$ & $1.02 \pm 0.2$ & $>20$ & 4.7 & 2.63 \\
\hline
\end{tabular}

${ }^{a}$ Inhibitory constants for recombinant enzymes were obtained by kinetic analysis of S1P production using variable concentration of sphingosine and a fixed concentration of ATP in the presence or absence of compounds as described previously. ${ }^{21}$ Selectivity for each compound was determined by dividing the $K_{\mathrm{m}} \mathrm{SphK} 2$ by the $K_{\mathrm{m}}$ of SphK1. and 2 was observed, suggesting that these are dual inhibitors. ${ }^{27}$ Interestingly, both of these compounds have the lowest cLogP and $\operatorname{cLogD}$ values in this set. It is predicted that this hydroxyl group mimics the interaction of one of the hydroxyl groups of sphingosine, leading to dual SphK1 and SphK2 inhibition (vide infra). As expected, the des-hydroxy naphthyl analogues restored SphK2 selectivity. SLC5081308 (7b) bearing a pentyl ether has a $K_{\mathrm{i}}$ of 7.2 and $0.98 \mu \mathrm{M}$ with hSphK1 and 2 , respectively, affording 7 -fold selectivity toward SphK2. The hexyl derivative SLC5011416 (7c) is slightly less potent and selective. In contrast, the para-trifluoromethylbenzyl ether derivative SLC5091592 $(7 \mathbf{n})$ has a $K_{\mathrm{i}}$ of $1.0 \mu \mathrm{M}$ and over 20 -fold selectivity toward $\mathrm{hSphK2}$. In terms of pharmacokinetic parameters, the new inhibitors in Table 2 are less lipophilic $(\operatorname{cog} \mathrm{P}=2.3-4.7)$ than the lead compound SLR080811 (cLogP = 5.2) or native substrate, sphingosine $(\operatorname{cog} P=5.96)$. We then compared the activity of these inhibitors against known SphK inhibitors. As shown in Figure 2, Genzyme 9ab and PF-543 are potent SphK1 inhibitors, whereas SLC5091592 (7n) is clearly a SphK2 selective inhibitor.

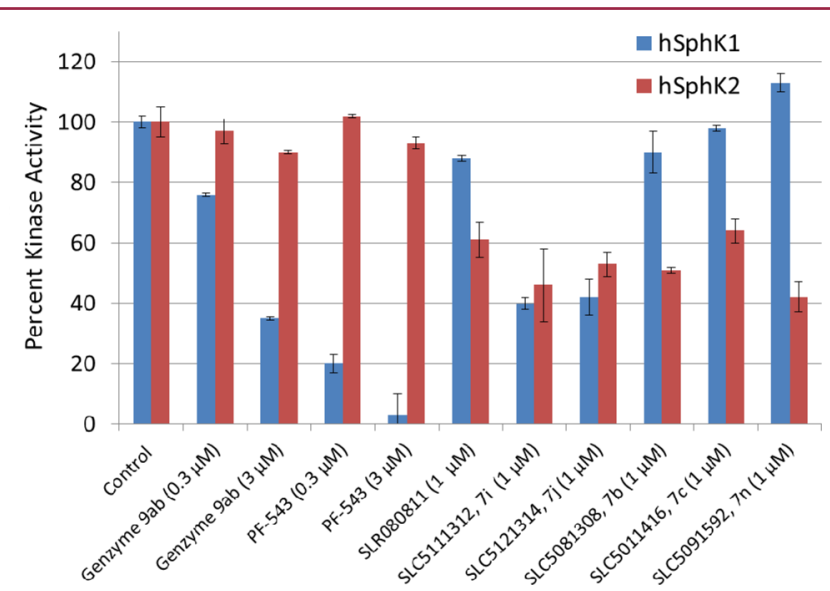

Figure 2. Sphingosine kinase activity of select inhibitors.

To understand the binding mode of these compounds, a homology model of hSphK2 was generated based on the published crystal structure of hSphK1 in a complex with ADP and magnesium (PDB ID: $3 \mathrm{VZB}){ }^{28}$ We modified ADP to ATP by adding a phosphate group to the $\mathrm{ADP}$ of the crystal structure and energy minimized the resulting structure. Following the equilibration and validation of our hSphK2 homology model with ATP and $\mathrm{Mg}^{2+}$ bound, SLC5091592 (7n), SLC5081308 (7b), and SLC5111312 (7i) were docked into the substrate-binding cavity. Our research has previously shown that these analogues are competitive with sphingosine and not with ATP. ${ }^{21}$ As illustrated in Figure 3A, SLC5091592 (7n) adopts a "J-shape" conformation similar to the lipid portion of the sphingosine/SphK1 and PF543/SphK1 crystal structures. ${ }^{29}$ For SLC5091592 (7n) two hydrogen bonds are formed: guanidine to Asp211 and nitrogen (position 4) of the oxadiazole ring to Asp308. The cationic guanidine group is situated in an area surrounded by anionic residues (Asp) and the phosphate of ATP. In SLC5081308 (7b), a hydrogen bond is formed between Asp308 and the guanidine nitrogen of the pyrrolidine ring, indicating a slight change in position as caused by alteration of the tail region in the inhibitors (Figure 3A,B) and can relate to potency. In SLC5091592 (7n), a favorable $\pi$-stacking interaction between the naphthalene ring and Phe548 is observed, in addition to the benzyltrifluoromethyl "tail" being positioned in a hydrophobic pocket that is capped by 

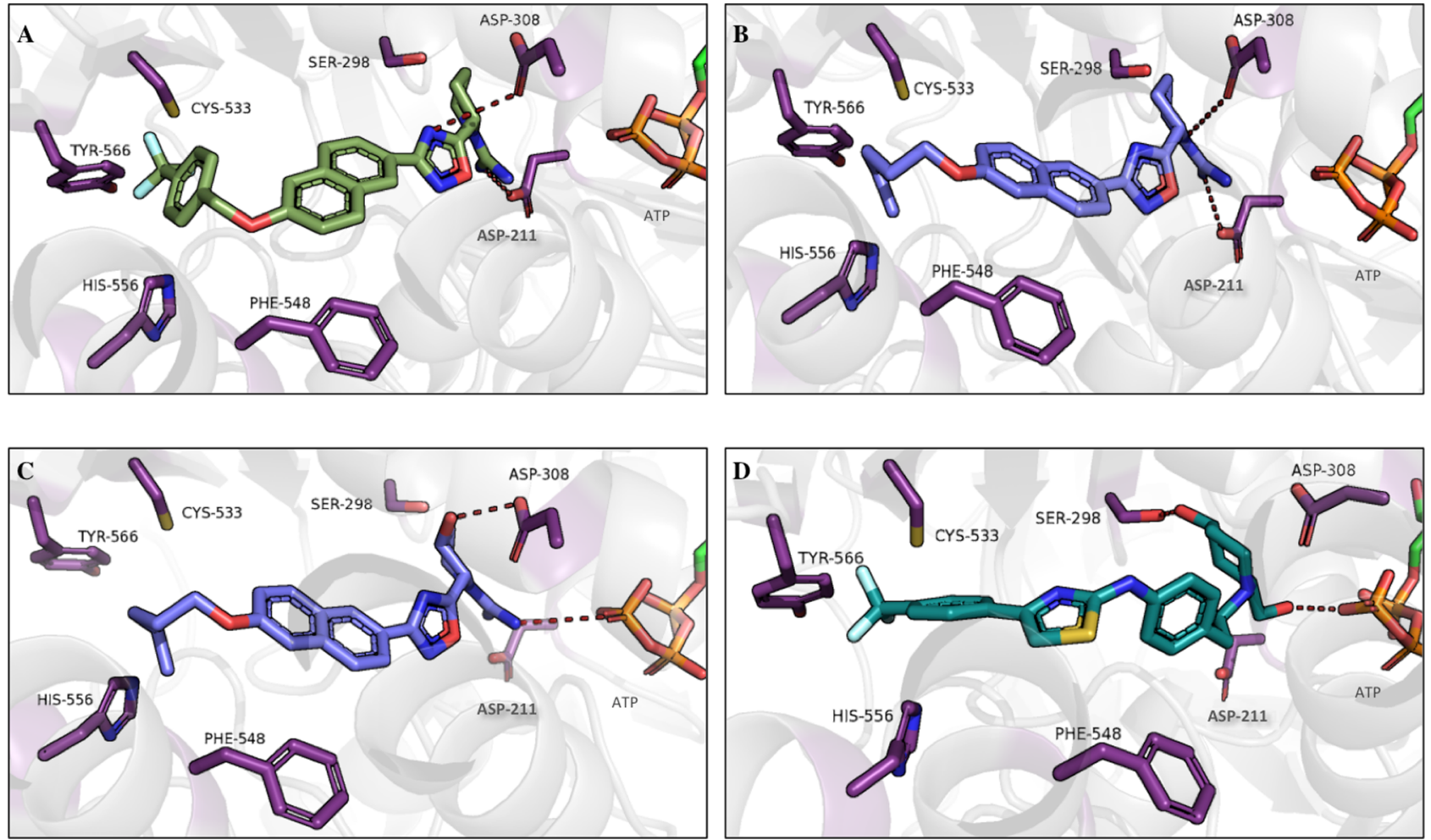

Figure 3. Docking of inhibitors into SphKs. (A) SLC5091592 (7n), (B) SLC5081308 (7b), (C) SLC5111312 (7i), and (D) Amgen 82 docked into a homology model of hSphK2. Key active site residues are labeled and shown as purple sticks, while ATP is shown as green sticks (colored by element). Hydrogen bonds are indicated with red dashes. Magnesium is not shown for clarity.

residues Cys533, Tyr566, and His556. Cys533 in hSphK2 corresponds to Phe288 in hSphK1 and is one of four residue differences in the hSphK1 and hSphK2 binding cavity. Finally, the conformationally restricted pyrrolidine hydroxyl group present in SLC5111312 (7i) forms a hydrogen bond with Asp308 of SphK2 (Figure 3C), which is missing in SLC5081308 (7b) (Figure 3B), allowing it to function as a dual $\mathrm{SphK} 1 / \mathrm{SphK} 2$ inhibitor by moving the inhibitor up in the pocket and away from Asp211. Asp178 of SphK1 similarly forms this hydrogen bond with SLC5111312 (7i) (Figure S3, Supporting Information). Interestingly, in the cocrystal structure of sphingosine with SphK1, an analogous interaction between the internal hydroxyl group and Asp178 exists. ${ }^{28}$ This interaction in conjunction with our results indicates that the hydroxyl on SLC5111312 (7i) stabilizes interactions of the inhibitor in the top of the binding cavity near residues Asp308 and Ser298. These interactions weaken or remove electrostatic and polar interactions with Asp211 and impart dual SphK activity. To further validate our studies, we docked another dual inhibitor, Amgen 82, and found that a hydrogen bond exists between the piperidine hydroxyl group and Ser298, while the hydrogen bond to Asp308 or Asp211 is abolished (Figure 3D). The hydrogen bond with Ser298 moves Amgen 82 up into the binding pocket and away from Asp 211. The hydrogen bond between the Amgen 82 piperidine hydroxyl group and Ser298 acts similarly to the hydrogen bond between Asp308 and SLC5111312 (7i) in regards to overall ligand positioning in the binding cavity. As a result, dual Sphk activity is observed for both Amgen82 and SLC5111312 (7i).

In conclusion, we described the structure-activity relationship profile of naphthalene-based SphK2 inhibitors. A key discovery of our studies is SLC5091592 (7n), a potent analogue that incorporates a 4-trifluomethylbenzyl "tail" and displays increased selectivity ( $>20$-fold) toward SphK2 when compared to SLR080811. Molecular docking studies suggest that the inhibitors possess a binding mode similar to sphingosine in the ligand binding pocket and emphasize the role of the tail region of the pocket on SphK selectivity. Furthermore, our investigation identifies the importance of two other crucial interactions that impart SphK2 selectivity: a guanidine hydrogen bond to Asp211 and the removal of a pyrrolidine hydroxyl group that abolishes a hydrogen bond to Asp308. This work provides an avenue toward improved sphingosine kinase inhibitors.

\section{ASSOCIATED CONTENT}

\section{S Supporting Information}

The Supporting Information is available free of charge on the ACS Publications website at DOI: 10.1021/acsmedchemlett.5b00304.

Characterizations of compounds and molecular modeling information (PDF)

\section{AUTHOR INFORMATION}

\section{Corresponding Author}

*Phone: 540-231-5742. E-mail: santosw@vt.edu.

\section{Author Contributions}

All authors have given approval to the final version of the manuscript.

\section{Notes}

The authors declare the following competing financial interest(s): W.L.S. and K.R.L. are among the cofounders of SphynKx Therapeutics LLC, which was created to commercialize S1Prelated discoveries, including $\mathrm{SphK}$ inhibitors, discovered and characterized in their laboratories. The compounds described in 
this manuscript are included in a patent application (PCT/ US2013/025341) licensed to SphynKx.

\section{ACKNOWLEDGMENTS}

The work was supported by NIH Grants R01 GM104366 and R01 GM067958.

\section{ABBREVIATIONS}

Sph, sphingosine; S1P, sphingosine-1-phosphate; SphK, sphingosine kinase

\section{REFERENCES}

(1) Spiegel, S.; Milstein, S. Sphingosine-1-phosphate: signaling inside and out. FEBS Lett. 2000, 476, 55-57.

(2) Spiegel, S.; Milstien, S. Sphingosine 1-phosphate, a key cell signaling molecule. J. Biol. Chem. 2002, 277, 25851-25854.

(3) Cohen, J. A.; Barkhof, F.; Comi, G.; Hartung, H. P.; Khatri, B. O.; Montalban, X.; Pelletier, J.; Capra, R.; Gallo, P.; Izquierdo, G.; TielWilck, K.; de Vera, A.; Jin, J.; Stites, T.; Wu, S.; Aradhye, S.; Kappos, L. Oral fingolimod or intramuscular interferon for relapsing multiple sclerosis. N. Engl. J. Med. 2010, 362, 402-15.

(4) Kappos, L.; Radue, E. W.; O’Connor, P.; Polman, C.; Hohlfeld, R.; Calabresi, P.; Selmaj, K.; Agoropoulou, C.; Leyk, M.; Zhang-Auberson, L.; Burtin, P. A placebo-controlled trial of oral fingolimod in relapsing multiple sclerosis. N. Engl. J. Med. 2010, 362, 387-401.

(5) Neubauer, H. A.; Pitson, S. M. Roles, regulation and inhibitors of sphingosine kinase 2. FEBS J. 2013, 280, 5317-36.

(6) Bigaud, M.; Guerini, D.; Billich, A.; Bassilana, F.; Brinkmann, V. Second generation S1P pathway modulators: research strategies and clinical developments. Biochim. Biophys. Acta, Mol. Cell Biol. Lipids 2014, 1841, 745-58.

(7) Takuwa, N.; Du, W.; Kaneko, E.; Okamoto, Y.; Yoshioka, K.; Takuwa, Y. Tumor-suppressive sphingosine-1-phosphate receptor-2 counteracting tumor-promoting sphingosine-1-phosphate receptor-1 and sphingosine kinase 1. Am. J. Cancer Res. 2011, 1, 460-481.

(8) Kunkel, G. T.; Maceyka, M.; Milstien, S.; S, S. Targeting the sphingosine-1-phosphate axis in cancer, inflammation and beyond. Nat. Rev. Drug Discovery 2013, 12, 688-702.

(9) Zhang, Y.; Berka, V.; Song, A.; Sun, K.; Wang, W.; Zhang, W.; Ning, C.; Li, C.; Zhang, Q.; Bogdanov, M.; Alexander, D. C.; Milburn, M. V.; Ahmed, M. H.; Lin, H.; Idowu, M.; Zhang, J.; Kato, G. J.; Abdulmalik, O. Y.; Zhang, W.; Dowhan, W.; Kellems, R. E.; Zhang, P.; Jin, J.; Safo, M.; Tsai, A. L.; Juneja, H. S.; Xia, Y. Elevated sphingosine-1-phosphate promotes sickling and sickle cell disease progression. J. Clin. Invest. 2014, $124,2750-61$.

(10) Takasugi, N.; Sasaki, T.; Suzuki, K.; Osawa, S.; Isshiki, H.; Hori, Y.; Shimada, N.; Higo, T.; Yokoshima, S.; Fukuyama, T.; Lee, V. M.; Trojanowski,J. Q.; Tomita, T.; Iwatsubo, T. BACE1 activity is modulated by cell-associated sphingosine-1-phosphate. J. Neurosci. 2011, 31, 68507.

(11) Visentin, B.; Vekich, J. A.; Sibbald, B. J.; Cavalli, A. L.; Moreno, K. M.; Matteo, R. G.; Garland, W. A.; Lu, Y.; Yu, S.; Hall, H. S.; Kundra, V.; Mills, G. B.; Sabbadini, R. A. Validation of an anti-sphingosine-1phosphate antibody as a potential therapeutic in reducing growth, invasion, and angiogenesis in multiple tumor lineages. Cancer Cell 2006, 9, 225-38.

(12) Santos, W. L.; Lynch, K. R. Drugging sphingosine kinases. ACS Chem. Biol. 2015, 10, 225-33.

(13) Plano, D.; Amin, S.; Sharma, A. K. Importance of sphingosine kinase $(\mathrm{SphK})$ as a target in developing cancer therapeutics and recent developments in the synthesis of novel SphK inhibitors. J. Med. Chem. 2014, 57, 5509-24.

(14) Rex, K.; Jeffries, S.; Brown, M. L.; Carlson, T.; Coxon, A.; Fajardo, F.; Frank, B.; Gustin, D.; Kamb, A.; Kassner, P. D.; Li, S.; Li, Y.; Morgenstern, K.; Plant, M.; Quon, K.; Ruefli-Brasse, A.; Schmidt, J.; Swearingen, E.; Walker, N.; Wang, Z.; Watson, J. E.; Wickramasinghe, D.;
Wong, M.; Xu, G.; Wesche, H. Sphingosine kinase activity is not required for tumor cell viability. PLoS One 2013, 8, e68328.

(15) French, K. J.; Zhuang, Y.; Maines, L. W.; Gao, P.; Wang, W.; Beljanski, V.; Upson, J. J.; Green, C. L.; Keller, S. N.; Smith, C. D. Pharmacology and Antitumor Activity of ABC294640, a Selective Inhibitor of Sphingosine Kinase-2. J. Pharmacol. Exp. Ther. 2010, 333, 129-139.

(16) Beljanski, V.; Knaak, C.; Smith, C. D. A novel sphingosine kinase inhibitor induces autophagy in tumor cells. J. Pharmacol. Exp. Ther. 2010, 333, 454-64.

(17) Antoon, J. W.; White, M. D.; Meacham, W. D.; Slaughter, E. M.; Muir, S. E.; Elliott, S.; Rhodes, L. V.; Ashe, H. B.; Wiese, T. E.; Smith, C. D.; Burow, M. E.; Beckman, B. S. Antiestrogenic effects of the novel sphingosine kinase-2 inhibitor ABC294640. Endocrinology 2010, 151, 5124-35.

(18) Raje, M. R.; Knott, K.; Kharel, Y.; Bissel, P.; Lynch, K. R.; Santos, W. L. Design, synthesis and biological activity of sphingosine kinase 2 selective inhibitors. Bioorg. Med. Chem. 2012, 20, 183-194.

(19) Knott, K.; Kharel, Y.; Raje, M. R.; Lynch, K. R.; Santos, W. L. Effect of alkyl chain length on sphingosine kinase 2 selectivity. Bioorg. Med. Chem. Lett. 2012, 22, 6817-6820.

(20) Patwardhan, N. N.; Morris, E. A.; Kharel, Y.; Raje, M. R.; Gao, M.; Tomsig, J. L.; Lynch, K. R.; Santos, W. L. Structure-Activity Relationship Studies and in Vivo Activity of Guanidine-Based Sphingosine Kinase Inhibitors: Discovery of SphK1- and SphK2-Selective Inhibitors. J. Med. Chem. 2015, 58, 1879-99.

(21) Kharel, Y.; Raje, M.; Gao, M.; Gellett, A. M.; Tomsig, J. L.; Lynch, K. R.; Santos, W. L. Sphingosine kinase type 2 inhibition elevates circulating sphingosine 1-phosphate. Biochem. J. 2012, 447, 149-57.

(22) Zemann, B.; Kinzel, B.; Muller, M.; Reuschel, R.; Mechtcheriakova, D.; Urtz, N.; Bornancin, F.; Baumruker, T.; Billich, A. Sphingosine kinase type 2 is essential for lymphopenia induced by the immunomodulatory drug FTY720. Blood 2006, 107, 1454-1458.

(23) Olivera, A.; Mizugishi, K.; Tikhonova, A.; Ciaccia, L.; Odom, S.; Proia, R. L.; Rivera, J. The sphingosine kinase-sphingosine-1-phosphate axis is a determinant of mast cell function and anaphylaxis. Immunity 2007, 26, 287-97.

(24) Sensken, S. C.; Bode, C.; Nagarajan, M.; Peest, U.; Pabst, O.; Graler, M. H. Redistribution of sphingosine 1-phosphate by sphingosine kinase 2 contributes to lymphopenia. J. Immunol. 2010, 184, 4133-42.

(25) Congdon, M. D.; Childress, E. S.; Patwardhan, N. N.; Gumkowski, J.; Morris, E. A.; Kharel, Y.; Lynch, K. R.; Santos, W. L. Structure-activity relationship studies of the lipophilic tail region of sphingosine kinase 2 inhibitors. Bioorg. Med. Chem. Lett. 2015, 25, 4956-60.

(26) Kharel, Y.; Mathews, T. P.; Kennedy, A. J.; Houck, J. D.; Macdonald, T. L.; Lynch, K. R. A rapid assay for assessment of sphingosine kinase inhibitors and substrates. Anal. Biochem. 2011, 411, 230-235.

(27) Kharel, Y.; Morris, E. A.; Congdon, M. D.; Thorpe, S. B.; Tomsig, J. L.; Santos, W. L.; Lynch, K. R. Sphingosine Kinase 2 Inhibition and Blood Sphingosine 1-Phosphate Levels. J. Pharmacol. Exp. Ther. 2015, 355, 2331.

(28) Wang, Z.; Min, X.; Xiao, S. H.; Johnstone, S.; Romanow, W.; Meininger, D.; Xu, H.; Liu, J.; Dai, J.; An, S.; Thibault, S.; Walker, N. Molecular basis of sphingosine kinase 1 substrate recognition and catalysis. Structure 2013, 21, 798-809.

(29) Wang, J.; Knapp, S.; Pyne, N. J.; Pyne, S.; Elkins, J. M. Crystal Structure of Sphingosine Kinase 1 with PF-543. ACS Med. Chem. Lett. 2014, 5, 1329-33. 